\title{
Una historia anacrónica de las mujeres. Milena Rodríguez Gutiérrez y su construcción académica de una genealogía poética
}

\author{
Luciana Del Gizzo \\ Instituto de Literatura Hispanoamericana, Universidad de Buenos Aires - \\ Conicet, Argentina
}

\begin{abstract}
"Ser vanguardista era ganarse el cartel de loca", declaró Dalila Puzzovio en una entrevista reciente al recordar la experiencia del Instituto Di Tella. Eso era en los sesenta. Antes, durante y después, incluso ahora, el mote de "loca" surge con facilidad frente a cada actividad que deseamos desempeñar fuera de lo esperable. Porque hay que pelear el espacio, reivindicar un lugar, llamar la atención. Y entonces: loca, para obturar definitivamente esa reivindicación. Lo experimentamos todas con más o menos frecuencia. En esas circunstancias - que imagino más complicadas cuanto más atrás en el tiempo-, la complicación de las mujeres para sostener una actividad con hegemonía masculina no solo radicaba en su relegación, sino también en la dificultad de sostener el deseo, la voluntad, la perseverancia en mundos con roles muy delimitados y sin electrodomésticos ni anticonceptivos.
\end{abstract}

Es cierto que en los movimientos vanguardistas las mujeres se han contado con los dedos de una mano y prácticamente ninguna se aventuró solita, sin un hombre que la acompañara, en el mundo machote de los ismos donde el adjetivo "femenino" era peyorativo. Pero los motivos de ambas resistencias eran diferentes: lo femenino como sinónimo de debilidad o sensibilidad y sus múltiples variantes, como "la poesía viril" que los vanguardistas reivindican frecuentemente, era una reacción contra el ideal romántico y modernista que en algunos casos desbordaba en misoginias individuales; la ausencia de mujeres no radicaba en un rechazo orgánico, sino más bien en lo que podríamos llamar una cuestión de tempo u ocasión: la ruptura de las formas - de esas formas-, el endiosamiento de la velocidad y los fierros - automovilísticos o bélicoso la reivindicación sexual que volvía a objetivarla, entre otros planteos disruptivos, dejaban en claro que esa no era su revolución en ese momento en que todavía faltaba lograr los derechos políticos y civiles.

Lo primero que afirma Peter Bürger (2000) para enfocar el estudio de la vanguardia es que las categorías estéticas son históricas. Probablemente, las sociales también lo sean, pero con un ritmo distinto de transformación. Y la categoría de género se ha movido con sorprendente parsimonia hasta los últimos años. La historia del feminismo muestra un avance lento y con esfuerzos a veces desmedidos, pero sin pausa, desde mediados del siglo XIX hasta mediados del XX, y una aceleración de la reivindicación de los derechos igualitarios en su final. Luego de esa gestación, no caben dudas de 
que este es el tiempo de la revolución de las mujeres, la ocasión de reivindicarnos una libertad sin condicionamientos de rol, cuyo resultado sea la autonomía de desarrollar cualquier actividad sin tener que colgarse ningún cartel de loca. Así de simple -y de complicado-.

Ahora bien, toda revolución rompe con un pasado, determina un nuevo comienzo de la historia y construye una genealogía, que es a su vez un reacomodamiento del pasado para autorizar el presente. En esa búsqueda desenfrenada de precursoras, el anacronismo productivo es una herramienta fundamental que está a la orden del día. Me refiero al concepto que Didi-Huberman propone para abordar la historia de las imágenes, pero que puede extenderse a una conceptualización de la historia en general: el conocimiento histórico sería un proceso al revés del orden cronológico, "un retroceso en el tiempo", es decir, estrictamente, un anacronismo, [...] una anamnesia cronológica, regresión del tiempo a contrario del orden de los acontecimientos" (Didi-Huberman, 2011: 54-55). En este sentido, la búsqueda de precursoras es un remontarse al pasado desde "nuestros actos de conocimiento que están en el presente" (2011: 54-55), actos a los que agregaría una emocionalidad, una discursividad y una cosmovisión actual.

La revisión que nos lleva a hurgar en la historia en busca de mujeres que ejercieron su libertad de acción a pesar de todo produce una reconfiguración del pasado que es anacrónica por naturaleza, en tanto que desanda el trayecto cronológico desde una discursividad, un "acto de conocimiento" (2011: 55), completamente impensable en la actualidad de esos pasados: la posibilidad de que las mujeres reescriban la historia con protagonistas de su género. "Ante una imagen — tan antigua como sea-el presente no cesa jamás de reconfigurarse [...]. Ante una imagen - tan reciente, tan contemporánea como sea-, el pasado no cesa nunca de reconfigurarse, dado que esta imagen sólo deviene pensable en una construcción de la memoria, cuando no de la obsesión" (2011:32): es esa reconfiguración del pasado por el presente y del presente por el pasado lo que entra en el juego anacrónico de conformar una genealogía para una concepción nueva, revolucionaria.

"El anacronismo es necesario, el anacronismo es fecundo, cuando el pasado se muestra insuficiente, y constituye incluso, un obstáculo para la comprensión de sí mismo" (2011:43). Si no hay antecedente en esta nueva concepción de las mujeres, entonces, el pasado tal cual lo hemos conocido no alcanza y es preciso revisarlo. Ese anacronismo es el que ejerce una y otra vez Milena Rodríguez Gutiérrez (2012) cuando hurga en el pasado en busca de poetas cubanas y latinoamericanas dispersas, muchas relegadas por la historia, para reconfigurar un pasado de mujeres que a la vez autorice un presente, su propio presente. En su labor académica de investigación, en su trabajo crítico como antóloga, en su escritura poética, Rodríguez Gutiérrez busca permanentemente a sus precursoras, ya sea que comparta su poética o no, porque la antecedieron por el único hecho de haber levantado la pluma.

Si ejercer la vanguardia era un acto provocador por demás, insurgente, más aún, insano, para una mujer en los años sesenta como señaló la artista conceptual Dalila Puzzovio (Picasso, Puzzovio, 2019), escribir lo fue en todos los tiempos para nosotras y nuestras congéneres. Por eso, sostener el deseo, la voluntad, la perseverancia era tarea ardua que, si irrefrenable, era pasible de caer en el olvido, ser relegada o recibir el cartel de loca. Una historia de la literatura de mujeres es entonces una historia anacrónica, un remontarse hacia el pasado desde una inquietud plagada de presente. Además, está compuesta por tantos elementos históricos como hiatos o quiebres, dado que estas escritoras, en general, no se vincularon en continuidades de precursoras ni en la sincronía de movimientos de mujeres. Se trata entonces de "un extraordinario montaje de tiempos heterogéneos que forman anacronismos" (Didi-Huberman, 2011: 39). 
Hurgar en la memoria, en tanto "tiempo que no es exactamente el pasado [...] que decanta el pasado de su exactitud" (2011: 60), que además es una memoria inconsciente dado que ha sido olvidada y reprimida, es lo que propone Milena Rodríguez Gutiérrez en Entre el cacharro doméstico y la vía láctea. Poetas cubanas y latinoamericanas (2012); una historia anacrónica y marginal, de poetas poco leídas y olvidadas por la crítica, que procura dar cuenta no solo de elementos en común, rasgos que definan lo que denomina una poesía femenina, sino también la perspectiva diferenciada de aquellas cuestiones que, como intelectual, académica y poeta, la desvelan.

Señalo esto porque creo que sus intereses obedecen a su condición de poeta académica, una figura que emerge cada vez con más fuerza y frecuencia, y que resulta preciso que empecemos a atender. En Argentina, puedo nombrar de memoria a Carlos Battilana, Anahí Mallol, Lucas Margarit, Silvio Mattoni, Mario Ortiz, la dupla Irene Sola-Facundo Ruiz y hay más; en Chile, Felipe Cussen y Diamela Eltit; y tantos otros como países hay en América Latina. Es necesario que la abordemos porque se trata de un emergente, de una situación particular, la de una ultra especialización de los estudios literarios combinada con - hay que decirlo- el repliegue del público masivo, que circunscribe a la literatura, y a la poesía en particular, a un círculo de entendidos cultores de una práctica propia de otro tiempo.

Marcada por una contradicción de origen frecuentemente los poetas acusan a la crítica académica de ininteligible, de hacer complicado el diáfano discurso poético, cuando en realidad temen, a su real aunque disgregado, poder de incidir en el canon; los académicos acusan a los poetas de no ser conscientes de sus propias operaciones, de ser demasiado sensibles o demasiado vanidosos, ${ }^{1}$ esta figura se define por esa tensión en la práctica, en tanto que poética y líneas de investigación, reflexión teórico-crítica y conocimiento lingüístico se cruzan y sobredeterminan. Así ocurre entre la coherente línea de investigación de Rodríguez Gutiérrez y su poética, porque el compendio de artículos académicos que recoge en Entre el cacharro doméstico y la vía láctea (2012) no es otra cosa que la construcción de esa genealogía de precursoras, de esa historia anacrónica que necesita para avalar su práctica como poeta.

Aunque el título del volumen, que toma de una reflexión de Fina García Marruz (La Habana, 1923), y su introducción lleven a suponer que el libro presentará poéticas que hacen de la inmanencia de lo cotidiano, de lo doméstico y las prácticas de las mujeres elementos que participan de lo trascendente, este es solo uno de sus rasgos y no el más sobresaliente. La operación central del libro es construir esa genealogía anacrónica, que se despliega no solo por la lectura de poetas cubanas conocidas y poco leídas, sino también por el ejercicio del anacronismo productivo. Así, Rodríguez Gutiérrez (2012) lee un feminismo de igualdad en poemas de Gertrudis Gómez de Avellaneda (1814-1873), Úrsula Céspedes de Escanaverino (1832-1874) y Adelaida del Mármol (1838-1857) que, de acuerdo con su propio análisis, realizan una reivindicación femenina cuestionando juicios masculinos y sociales sobre las mujeres, pero que en verdad no alcanzan el carácter colectivo y orgánico del movimiento que pugna por el acceso a derechos de las mujeres.

Su anacronismo productivo, entonces, consiste en adscribir ese carácter colectivo y orgánico, definiendo el feminismo de igualdad como una filosofía política que se abre paso por cauces impensados en los poemas que analiza. ${ }^{2}$ Una operación similar se advierte en "La correspondencia de Gertrudis Gómez de Avellaneda a Cepeda: problemas en torno a la transmisión del texto" (2012: 40-64). Allí, al comparar las distintas ediciones de las cartas, da cuenta de "manipulaciones y tergiversaciones [...]; filtros paternalistas y sexistas [...] que se sintieron autorizados a seleccionar, juzgar y decidir por encima de la voluntad textual de la escritora" (2012: 63), sin detenerse a considerar el contexto de edición, la dificultad de que textos de alto voltaje erótico circularan en
1. Algo así señala Felipe Cussen al reflexionar sobre su propia condición de "poeta y académico": "las tensiones entre estos distintos campos de acción. En gran parte se deben, evidentemente, a los prejuicios sobre estos roles: muchos poetas acusan a los académicos de estar apoltronados en nuestras oficinas y fantasean con que nos reunimos todas las tardes a tomar té con Matías Rivas para conspirar y decidir los destinos de la literatura nacional (yo nunca me he juntado a tomar té con él; solo una vez a comer). Y los académicos también caen en lo mismo cuando crean una imagen del poeta como un ser inocente, hipersensible y, lo más errado, buena persona" (2015: s.p.). Esta tensión confluye en la misma figura del poeta académico, que entiendo a diferencia de Cussen sin nexo coordinante.
2. Llama la atención la elección del título de este artículo, "Filosofía en el tocador: poetas cubanas del siglo XIX” (Rodríguez Gutiérrez, 2012: 15-39), porque si bien la autora juega con la idea de una filosofía íntima, doméstica en los poemas, no hace referencias al libro del Marqués de Sade el cual, por su contenido pornográfico, su sarcasmo y su violencia hacia el personaje de Eugenia, está muy lejos de ser una referencia para el feminismo de igualdad. 
3. Según se informa en el mismo texto, de acuerdo al prólogo de la edición original, esta correspondencia fue entregada al editor, "Lorenzo Cruz de Fuentes, catedrático del Instituto Almonte, pueblo de Huelva en el que tenía su casa de veraneo la familia Cepeda, [...], al parecer, por la viuda de Ignacio de Cepeda, María de Córdova y Govantes, a la muerte de Cepeda y por indicación expresa de éste" (2012: 45). Es de suponer que la viuda pusiera condiciones para autorizar la publicación. 4. Véase Rodríguez Gutiérrez, M. (2012).Feminidad, vanguardia y poesía o ¿hubo alguna vez mujeres vanguardistas? En A través de la vanguardia hispanoamericana orígenes, desarrollos, transformaciones, pp. 223-243. España, Universitat Rovira I Virgili.

5. Véase "El compromiso poético de Fina García Marruz" (Rodríguez Gutiérrez, 2012: 130-153). ámbitos literarios "decentes" a principios de siglo XX y las limitaciones que muchas veces imponen los derechohabientes para habilitar la publicación, como es muy posible que haya sido el caso. ${ }^{3}$

Otra vez se impone la perspectiva del presente al juzgar la ausencia de las mujeres en las vanguardias, cuando coincide con George Yúdice (1992) en la existencia de cierta misoginia en estos movimientos, ${ }^{4}$ algo a lo que me he referido en el inicio de este artículo. Y siguen este tipo de estrategias, aunque Rodríguez Gutiérrez no se queda en escudriñar los rasgos paternalistas y sexistas del pasado, que ya conocemos porque de otro modo no tendríamos ahora una revolución de mujeres. Transforma el conjunto de poetas de esa historia anacrónica en verdaderas precursoras al leer en las poesías sus propios intereses e, incluso, los rasgos de su poética.

Entonces, lee en la poesía de Fina García Marruz un cruce entre la perspectiva origenista - de rasgos trascendentalistas-y "la dimensión femenina, o, incluso, la impronta de género" (Rodríguez Gutiérrez, 2012: 131). El poema que analiza, "Las ganas de salir", expone un problema que atañe principalmente a las mujeres en el orden patriarcal, el tedio del encierro doméstico, la imposibilidad de irse por las responsabilidades de la casa y la transformación de ese tedio en una evasión productiva gracias al deseo y la imaginación. ${ }^{5}$ Es la misma reclusión que aparece muy temprano en la poesía de Rodríguez Gutiérrez, aunque la evasión despierta aquí una obsesión que raya lo siniestro de ese deseo demorado y se vuelve venganza trascendental y grito silencioso de guerra de género:

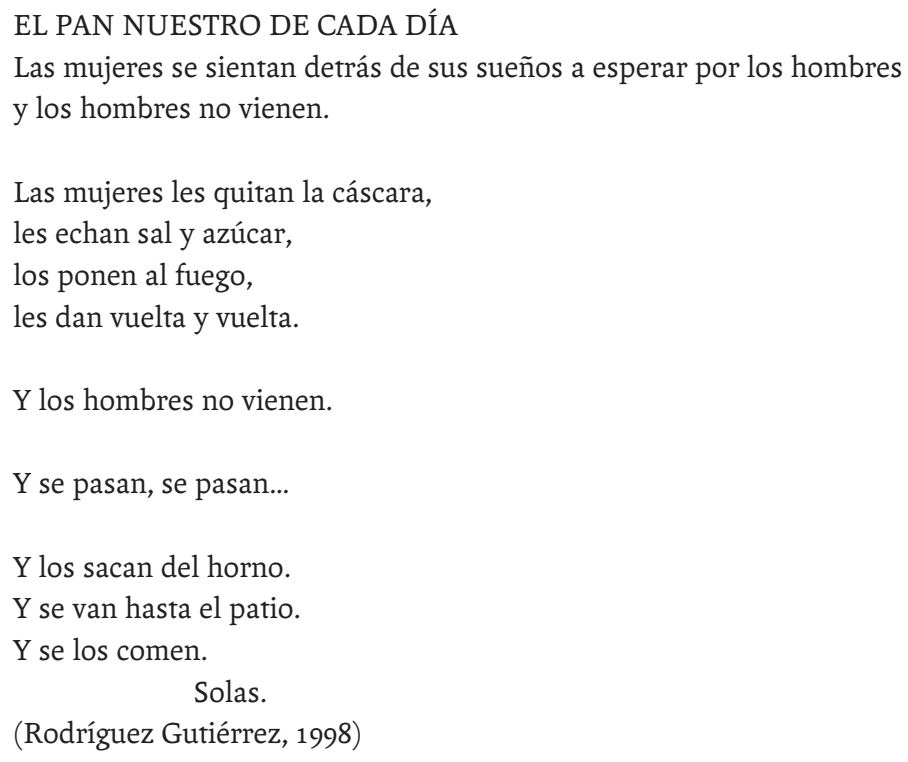

Algo similar ocurre con el cruce entre lo político, lo nacional, la insularidad cubana y la perspectiva de género. Rodríguez Gutiérrez encuentra entonces el punto de vista marginal de las mujeres sobre el proceso de independencia de Cuba, que se detiene en las ruinas y la destrucción que dejaron las guerras, así como su papel en el proceso de construcción de la identidad nacional, particularmente, en las poéticas de Mercedes Matamoros (1851-1906) y Aurelia Castillo de González (1842-1920). ${ }^{6}$ A su vez, señala las transformaciones de la coyuntura que llevaron a Gertrudis Gómez de Avellaneda a reescribir el poema "A S. M. La Reina, cuando la declaración de su mayoría", demostrando la conciencia política que manejaba la poeta. ${ }^{7}$ El tema de la insularidad cubana, el deseo del contacto con lo otro extranjero y su contrapartida, la constitución de la cubanidad también, adquiere una perspectiva diferente si se lo aborda desde el marginalidad: poetas cubanas en torno al proceso independentista de finales del XIX. Mercedes Matamoros y Aurelia Castillo de González" (Rodríguez Gutiérrez, 2012: 94-110) 7. Véase "La reina y la libertad: reflexiones en torno al poema "A S M. La Reina, cuando la declaración de su mayoría", de Gertrudis Gómez de Avellaneda” Rodríguez Gutiérrez, M. (2012: 65-79). 
punto de vista de poetas como Luisa Pérez de Zambrana, que no soslaya lo real cubano en bruto, lo siniestro de la cubanidad. ${ }^{8}$

Esta cuestión es central en la poética de Ramírez Gutiérrez en tanto que, como cubana exiliada, el tema de la insularidad, sus límites nítidos desde la isla y problematizados desde el exterior por la dispersión de los cubanos en el mundo resultan recurrentes, sobre todo en su poemario de 2006, El otro lado. La restricción de los límites marítimos y el deseo de lo otro extranjero se vuelve trascendentes en los poemas "Inocencia entre las olas" (Rodríguez Gutiérrez, 2006: 26) y "Mar adentro":

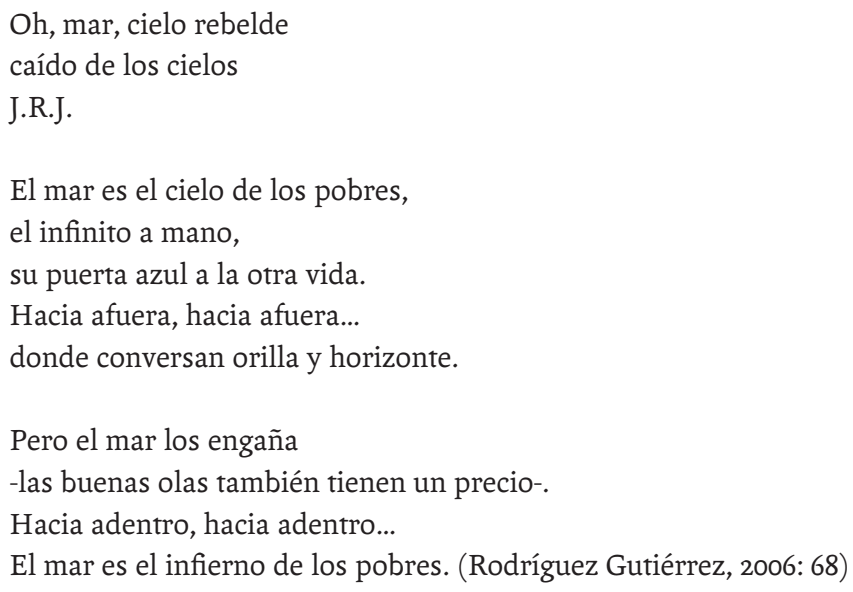

La dimensión política de este poema está señalada por la poesía que abre la sección "Islas" del libro, donde se pregunta "¿Quién dijo que las islas son estatuas? / Hay islas que del tiempo se alimentan, / que suben y que bajan por la cuesta / del difícil camino de ser patria" (Rodríguez Gutiérrez, 2006: 17). Interrogantes similares surgen sobre lo nacional con una impronta más casera en "Preguntas desde el otro lado de la cocina”: "¿Cuál es la temperatura de un país? / ¿Cuánta sal hay que echarle, / o cuánta azúcar, / para que esté en su punto? /¿Debe hervir un país / o debe cocinarse a fuego lento? / Y, sobre todo, quién se atreve / a probarlo y decir: / Está ya listo. / Traigan sus platos, por favor, / y buen provecho" (2006: 64).

El territorio insular se transforma, muta, en el dibujo de un mapa conformado por todas las geografías donde habitan los cubanos en el extranjero, desde que el exilio permite advertir que la cubanía es móvil, se encuentra en cada retazo íntimo de poetas como Mercedes García Tudurí (1904-1997), Julia Rodríguez Tomeu (1913-2005), Nivaria Tejera (1929), Isel Rivero (1941), Belkis Cuza Malé (1942), Magalí Alabau (1945), Lourdes Gil (1950) y María Elena Cruz Varela (1953), que ponen en cuestión la idea esencialista de nación, según Rodríguez Gutiérrez analiza en "Maneras de escribir el dulce nombre de la patria: poetas cubanas en el exilio" (2012:169-189) y "En la periferia del exilio: la poesía de Julia Rodríguez Tomeu" (2012: 154-168).

Este problema, que lógicamente atraviesa poéticas de mujeres y hombres en el exilio por igual, y que es común en la literatura latinoamericana, no deja de tener una impronta de género en la perspectiva de la poeta académica cubana, dado que el exilio se da por partida doble en las mujeres inmigrantes: a la extranjería física se le superpone una extranjería simbólica en una historia y una cultura, compuesta por espacios y discursividades de creación y de circulación masculina. ${ }^{9}$ El mismo descentramiento se encuentra en el poema que dedica a Granada, ciudad en la que reside desde 1997: "Va bien esta ciudad, según se dice, / aunque a mí no me sirven sus horarios: / cuando llegan las seis a sus relojes/ dan las doce en el centro de mi alma. / Me pongo mal su acento, sus hombres, sus abrigos. / Corren fuera de mi
8. Véase " "En la bahía”, un poema olvidado de Luisa Pérez de Zambrana: una visión distinta sobre lo otro cubano". (Rodríguez Gutiérrez, 2012: 80-93).
9. Véase “Poetas transatlánticas: hispanoamericanas en la España de hoy. Cristina Peri Rossi, Ana Beccié, Isel Rivero" (Rodríguez Gutiérrez, 2012: 296-333). 
idioma sus palabras [...] / Aquí ya no soy yo sino mi isla / y su dolor exótico, sin marca. / Y a pesar de los amigos que son ciertos / me vuelvo mar a veces, hago agua" (Rodríguez Gutiérrez, 2001: 41).

De este modo, Milena Rodríguez Gutiérrez construye una poética y define una línea de investigación de forma interdependiente: su historia anacrónica de poetas mujeres es un modo de legitimar su propia práctica literaria, en tanto que como mujer, cubana y exiliada levanta la pluma con el mismo legítimo derecho que sus antepasadas que, como ella, tenían algo diverso que decir, que aportar. Su ejercicio historiográfico, además, es consciente de un rasgo adicional: en tanto que la poesía no goza de la popularidad y la estima masiva con las que contaba antaño, en tanto que es consciente de su circulación en ámbitos especializados y de que el lugar central lo ocupa desde hace tiempo la narrativa, la autora sabe que escribe una historia anacrónica y marginal por partida doble, de poesía y mujeres, de mujeres poetas, por una mujer poeta académica.

Su poética y su investigación se cruzan, por lo tanto, en los mismos intereses, pero también en un mismo estilo que incluye la afirmación abierta y valiente del punto de vista personal, que discute con posiciones hegemónicas masculinas, que propone lecturas íntimas y trascendentes a la vez, y que apuesta por la claridad en uno y otro discurso. En la producción académica, este último rasgo redobla su valor si consideramos que suele ser poco frecuente, la mayor parte de las veces, por deformación profesional, pero en ocasiones, por el ejercicio de un oscurantismo en el que se oculta la soberbia de escribir solo para entendidos y que, en verdad, no hace más que cerrar el círculo y cortar amarras con el conjunto social al que se debe la universidad. La literatura, y la poesía en particular, antes de ser enseñadas, necesitan ser comunicadas, transmitidas, para lo cual se requiere el esfuerzo de ejercitar un lenguaje accesible que, como aquí se demuestra, no atenta contra la complejidad de las hipótesis.

Finalmente, Rodríguez Gutiérrez busca y encuentra rasgos de lo que llama una poesía femenina: una mirada descentrada, marginal, que enfoca sus puntos de interés sin jerarquizarlos y que utiliza figuras retóricas propias, como la llamada "estrategia de subvaloración", que implica presentar al yo poético sin atractivo o mérito, o caracterizar la escritura poética propia como menor y sin importancia. Me pregunto si este recurso es una genuina estrategia de la poesía de las mujeres, una figura retórica, o si es producto, junto con el punto de vista marginal, de los milenios de sometimiento que padecimos, para el cual una de las principales tácticas consistió en hacernos creer, desde lo más interno de nuestra subjetividad, que carecemos de méritos y, en consecuencia, no merecemos. Acaso sea necesario aceptar que no es solo retórica y superar esa des-conciencia que nos sacó de nuestro centro por tanto tiempo, para completar nuestra revolución y ejercer completamente la libertad de hacer y decir, para que todos podamos afirmar por fin como Dalila Puzzovio: "No soy ni hombre ni mujer: soy artista" (Picasso, Puzzovio: 2019). 


\section{Dibliografía}

»Bürger, P. (2000). Teoría de la vanguardia. Barcelona, Península.

"Cussen, F. (2015). Poeta y académico. Una breve autobiografía crítica. Ensayo leído en el seminario de crítica literaria El circo en llamas, Valparaíso. <En línea: http://www.lacallepassyo61.cl/2015/10/poeta-y-academico-una-breve.html> (Consulta: 10-12-2019).

»Didi-Huberman, G. (2011). Ante el tiempo. Historia del arte y anacronismo de las imágenes. Buenos Aires, Adriana Hidalgo Editora.

»Picasso, G. y Puzzovio D. (2019) “Dalila Puzzovio: 'Ser vanguardista es ganarse el cartel de loca”. En Noticias, 26 de junio. En línea: <https://noticias.perfil. com/2019/06/26/dalila-puzzovio-ser-vanguardista-es-ganarse-el-cartel-de-lo$\mathrm{ca} />$ (Consulta: 10/12/ 2019).

»Rodríguez Gutiérrez, M. (2012). Entre el cacharro doméstico y la vía láctea. Poetas cubanas e hispanoamericanas. Sevilla, Editorial Renacimiento.

" Rodríguez Gutiérrez, M. (1998). El pan nuestro de cada día. Granada, Universidad de Granada.

"Rodríguez Gutiérrez, M. (2001). Alicia en el país de lo ya visto. Granada, Diputación de Granada.

»Rodríguez Gutiérrez, M. (2006). El otro lado. Sevilla, Editorial Renacimiento.

» Yúdice, G. (1992). “Las vanguardias a partir de sus exclusiones”. En: Bacarisse, P. (ed.), Carnal Knowledge: Essays on theFlesh, Sex and Sexuality. Pittsburg, Tres Ríos: 187-197. 
